\title{
Personalidad de marca de los partidos políticos: propuesta de modelo
}

\section{Political Parties' Brand Personality: A suggested model}

\author{
Luis Araya-Castillo ${ }^{1}$ \\ M. Soledad Etchebarne L. ${ }^{2}$
}

\section{Resumen}

Los sistemas democráticos actuales se caracterizan por una baja participación política, en especial dentro del grupo de los jóvenes. Esta situación no es ajena a Chile, por cuanto los jóvenes se han automarginado del sistema político. Esto se debe a la percepción que tienen los jóvenes sobre el sistema político. Los jóvenes señalan que los partidos políticos no los representan, que no tienen confianza en los actores políticos y que su participación en los procesos eleccionarios no permite generar cambios. En este contexto, es imprescindible estudiar la decisión de los jóvenes de automarginarse de la política desde diferentes perspectivas teóricas. Con este objetivo se hace uso de la teoría de personalidad de marca, por cuanto se ha demostrado que las personas asignan cualidades humanas o rasgos de personalidad a las marcas. Dado esto, con la teoría de personalidad de marca se puede estudiar los rasgos de personalidad que los jóvenes atribuyen a los partidos políticos, y con esto, las razones que los han alejado de los procesos eleccionarios. En este contexto, se propone un modelo de personalidad de marca para los partidos políticos. Este modelo se construye en función de la percepción de los jóvenes universitarios, quienes deberían tener una opinión más favorable sobre el sistema político. El modelo propuesto cumple con los requisitos de la validez de contenido, validez convergente y validez divergente.

\section{Palabras clave}

Personalidad de marca, partidos políticos, modelo teórico, jóvenes, Chile.

\section{Abstract}

Current democratic systems are characterised by low political participation, especially among young people. This situation is not alien to Chile, where young people have marginalised themselves from the political system because of the perception they have of the system. Young people argue that political parties do not represent them, that they do not have confidence in politicians and that participating in elections does not change anything. In this context, it is essential to study, from various theoretical perspectives, young people's decision to marginalise themselves from politics. To this end, this article uses the theory of brand personality, where people assign human qualities or personality traits to brands. In this way, using the theory of brand personality, it is possible to study the personality traits which young people attribute to political parties, and thus why they have isolated themselves from electoral processes. This article proposes a model of brand personality for political parties, which was constructed based on the perception of university students, who would be expected to have a more positive opinion of the political system. The proposed model meets the requirements of content validity, convergent validity and divergent validity.

\section{Key words}

Brand personality, political parties, theoretical model, young people, Chile.

Artículo recibido el 15 de abril de 2014 y aprobado el 20 de agosto de 2014.

1 Universidad Mayor (Chile), Facultad de Emprendimiento y Negocios, Núcleo de Investigación Empresa, Sociedad y Tecnología (NEST). Correo electrónico: luis.araya@umayor.cl

2 Universidad de Chile, Facultad de Economía y Negocios, Departamento de Administración. Chile. Correo electrónico: setchebarne@unegocios.cl 
Los partidos políticos han desempeñado un rol muy importante en los procesos democráticos de los países. Sin embargo, en las últimas décadas se ha observado una disminución del interés de una parte importante de la ciudadanía, en particular de los jóvenes, por participar de los procesos e instancias tradicionales de una democracia. En el caso particular de Chile, donde se realiza la presente investigación, esto ha sido crítico en la última década. Un estudio de la Corporación de Estudios para Latinoamérica (en adelante CIEPLAN (2008) señalaba por ejemplo que el 78 \% de los jóvenes entre 18 y 29 años no se habían inscrito en los registros electorales. Ante situaciones como esta, surgen interrogantes como: ¿Los partidos políticos tendrán alguna responsabilidad sobre ello?, ¿qué piensan los jóvenes de los partidos políticos?, ¿qué estrategias están desarrollando los partidos políticos para encantar a estos jóvenes?, etc.

Con tales interrogantes, surge el interés de aplicar un modelo, que tradicionalmente ha sido utilizado en el ámbito del marketing, al ámbito de los partidos políticos, lo cual podría entregar información relevante para analizar y generar algunas propuestas en este respecto. Se trata del concepto de personalidad de marca desarrollado por Aaker (1997), definido como el conjunto de características humanas asociadas a una marca. Se propone un modelo de personalidad de marca para los partidos políticos, con el cual se pueda estudiar el comportamiento político de los jóvenes, y que contribuya a dar respuesta a algunas de las interrogantes planteadas en el párrafo anterior.

Para esto, en una primera etapa se revisa la literatura sobre personalidad de marca. Esto permite conocer las dimensiones de personalidad de marca consideradas por estudios que se han desarrollado en diferentes sectores culturales e industriales. Con esto se concluye que no se han elaborado modelos de personalidad de marca para los partidos políticos. Dado esto, se propone descubrir los rasgos de personalidad que los jóvenes atribuyen a los partidos políticos, a través de entrevistas en profundidad, cuestionarios semiestructurados y la opinión de expertos. Además, se realiza un análisis de pretest con el propósito de realizar el análisis de unidimensionalidad a las dimensiones propuestas.

En el primer apartado del artículo, se analizan aspectos relacionados con la democracia, el rol de los partidos políticos y la participación de los jóvenes. Este último punto es analizado principalmente en el contexto chileno donde se desarrolla la investigación. En el segundo apartado, se presenta en detalle el concepto de personalidad de marca, el modelo planteado por Aaker (1997) y se hace un análisis de algunas investigaciones que se han desarrollado en torno a este concepto en múltiples países y ámbitos de aplicación. Luego se explica la metodología que se aplica para proponer un modelo teórico de personalidad de marca para los partidos políticos. Posteriormente, este modelo se valida a través de la aplicación de un análisis de pretest. Finalmente, se describen las principales conclusiones del estudio, así como las limitaciones que presenta para ser aplicado en otros contextos culturales.

\section{Participación política de los jóvenes}

\section{Democracia y Partidos Políticos}

El concepto de democracia fue analizado por Schumpeter (1942), quien señala que es el instrumento institucional para llegar a decisiones políticas, en virtud del cual cada individuo logra el poder de decidir mediante una competencia que tiene por objeto el voto popular. El autor señala que el sistema económico capitalista posibilita más que ningún otro régimen político el desarrollo de la democracia por tratarse de sociedades abiertas donde la libertad individual es condición básica para el sistema económico, aunque, como él señala, el método democrático no garantiza mayor libertad individual.

Por otra parte, Dahl (1971) plantea dos dimensiones que debe tener la democracia: la primera, dice, relación con la competencia, en el sentido de que el gobierno debe estar constituido por líderes que compiten con éxito por el voto popular en elecciones periódicas. La segunda se refiere a la participación, no solo en términos de participa- 
ción electoral, sino que en una variedad de responsabilidades cívicas que directa, o indirectamente, potencian la civilidad en un régimen democrático. Es en esta última dimensión donde la democracia chilena se está debilitando, ya que encontramos que un número importante de ciudadanos, particularmente los jóvenes, se han automarginado del sistema no inscribiéndose en los registros electorales y no participando en los actos eleccionarios.

En los años 60 y 70, plantea Balardini (2005), la voluntad se entendía como motor de cambios radicales, y la política era la voluntad. Pero al pasar el tiempo, en los años 80 y 90, la participación tradicional se ve cada vez menos relevante, y como consecuencia de esto, la participación decae al mínimo. El mismo autor sostiene:

La política como lugar de transformación del mundo se invierte en los años 80 y 90, cuando la economía pasa a subordinarla y pretende convertirla en pura técnica y administración. La política como transformación quedó entonces desplazada porque se suponía - las cosas no se pueden cambiar. (Balardini, 2005, p.100)

Con relación a los partidos políticos y los votantes, tema que nos interesa para la presente investigación, resulta de interés revisar algunos planteamientos expuestos por Anthony Downs (1973) en su libro Teoría económica de la democracia, muchos de los cuales se encuentran plenamente vigentes, como podremos observar a continuación. En primer lugar, señala que el gran objetivo de los partidos políticos es ganarse los votos de los ciudadanos (ya sea para obtener la reelección o ser electos), por lo que deben encontrar relaciones entre lo que hacen y cómo estos actos permiten cambiar las preferencias de los electores. En segundo lugar, señala que un determinante clave de la evolución política de un país es la distribución de sus votantes a lo largo del espectro político. De ello depende que existan dos o más partidos principales, que la democracia conduzca a gobiernos estables o inestables y que se produzca una continua sustitución de partidos antiguos por nuevos o que estos tengan un rol secundario. En tercer lugar, y en relación a los votantes, Downs
(1973) introduce el concepto de racionalidad, señalando que las personas no toman la decisión de voto considerando toda la información disponible, sino que en realidad tomarán la decisión que maximizará su utilidad. Explica las condiciones en las que la abstención es racional y trata de valorar su impacto en la distribución del poder político. Cuando el costo de votar es nulo, se hace racional votar e irracional abstenerse. En este sentido, el rendimiento total que cada persona obtiene de votar depende de: a) Los beneficios que le reporta la democracia; b) hasta qué punto desea la victoria de un partido en particular; c) lo igualada que a su juicio es la opinión de los votantes; d) el número de ciudadanos que a su juicio acudirán a votar.

Cuando los individuos comparan sus costos y beneficios, unos votan y otros se abstienen. En el caso de votar lo pueden hacer por su partido favorito, por razones estratégicas, o incluso lo pueden hacer al azar. En contraste a esta situación de racionalidad económica, encontramos lo planteado por el modelo sociológico (Jensen y Meckling, 1994) donde los individuos son considerados como el producto de su ambiente cultural, y se presentan generalmente como víctimas sociales. Esta victimización se relaciona con la tendencia humana a negar responsabilidades personales, y a pensar que lo que les sucede está determinado por factores más allá de su control no pueden ser considerados responsables de sus acciones o de su situación en la vida. En el caso de la situación política, muchos jóvenes se victimizan y no actúan ni se involucran en procesos políticos porque tienen la convicción de que nada van a poder cambiar.

En democracia los partidos políticos son actores claves del proceso, cumpliendo un rol de representar a la ciudadanía con sus intereses, motivaciones y derechos ante el poder legislativo del Estado. Esto pareciera que no siempre se cumple, y la ciudadanía no se siente plenamente representada por los partidos políticos. En relación a este punto, Valenzuela (2008) argumenta que tanto en América Latina como en el resto del mundo, tanto a nivel de participación y de representación como a nivel de toma de decisiones, hay una crisis de legitimidad democrática. 
También, como decía ya Huneeus (2000):

Ha disminuido la intensidad de la participación política pues los ciudadanos no participan mayormente en las campañas electorales, pues no concurren a los actos públicos, no apoyan el trabajo electoral de los candidatos, solo se limitan a emitir el sufragio el día de la elección, ni tampoco se interesan en difundir sus preferencias sobre sus amigos o parientes. Los candidatos se encuentran ante la necesidad de tener que recurrir al trabajo de activistas pagados, perdiendo importancia la labor de los voluntarios, como fue el estilo de las campañas en el pasado. (p. 1)

El mismo autor hace referencia a cómo esta baja en la participación política a veces es compensada por un aumento en el voluntariado de diferentes organizaciones, y dice, por ejemplo, que "la Iglesia Católica en Chile puede movilizar a decenas de miles de jóvenes en un peregrinaje en homenaje a una santa criolla, algo que ni la coalición gobernante, ni la oposición están en condiciones de hacer".

Frente a esta realidad, resulta de interés distinguir entre representatividad con presencia y representación por evocación. Zapata (2008) señala que la primera se refiere a un grupo de individuos que sirven de medio para los efectos de hacer presente la voluntad de un grupo mayor de personas; y la segunda la define como la capacidad de una élite de visualizar, comprender, asumir y proyectar, eficazmente cuáles podrían ser los intereses y deseos del resto de la población. En este contexto, Zapata (2008) señala que la mayor o menor representatividad de una élite dependerá tanto de su capacidad para leer certeramente los estudios y encuestas como de su flexibilidad para responder a los cambios de la sociedad y los vaivenes de la opinión.

En un análisis crítico a los partidos políticos, Huneeus (2000), haciendo referencia a lo señalado por Dahrendorf (1997), dice que no todos los partidos políticos muestran un decidido interés de buscar las condiciones para mejorar la capacidad de atracción que tuvieron en el pasado. Reitera que muchos tienden a reducirlo a una cuestión de marketing o de estrategias de comunicación, creyendo que el ciudadano es un individuo que define sus comportamientos e intereses materiales de corto plazo y por emociones, de la misma manera que lo hace el consumidor. No se cree que el ciudadano es un sujeto multidimensional que tiene pasiones, emociones, intereses y lealtades colectivas - políticas, sociales, económicas o culturales- que lo llevan a actuar de una manera muy distinta a como lo haría un consumidor en un supermercado o en un mall.

No obstante lo anterior, se argumenta que las organizaciones políticas pueden hacer uso del marketing político para mantener una relación planificada con los electores (Barrientos, 2010). Esto porque el marketing político se enfoca en conocer las necesidades y deseos de los ciudadanos, lo que posibilita una relación de intercambio en las que las dos partes (los partidos y los electores) obtienen beneficios recíprocos (España y Rivera, 2012). Además, el marketing político se ha convertido en un medio para construir y afianzar la legitimidad de políticos, gobiernos, instituciones públicas y organizaciones sociales (Valdez, Huerta y Vergara, 2012). Esta situación es relevante para los partidos políticos, por cuanto se sostiene que la democracia está en decadencia, en parte, porque en muchas ocasiones la política electoral se reduce a trucos de comunicación (Beccassino, 2008).

\section{Participación de jóvenes}

Sandoval (2000) señala que los partidos políticos no concitan el interés de los jóvenes; no los representan ni parecen ocuparse de sus problemáticas específicas, y tampoco aparecen como una garantía para la supervivencia de la democracia. Los jóvenes se muestran desencantados con los mecanismos de representación, así lo señala la escasa relevancia que le otorgan a los partidos políticos en el mantenimiento de la vida democrática (Sandoval, 2000).

Hopenhayn (2004) afirma:

La modernidad y postmodernidad coloca a los jóvenes en un lugar de tensiones y contradicciones: más educación y menos acceso al empleo, más información y menos acceso a instancias de poder, mayor autonomía moral y menores opciones de 
autonomía efectiva, mayor brecha entre consumo simbólico y consumo material [etc.]. (p. 1)

Lo que condiciona la relación entre los jóvenes y las figuras de autoridad. Además en su trabajo observa, a partir de las Encuestas Nacionales de Juventud realizadas el año 2000 en Chile, Colombia, México y España, algunas tendencias que siguen los jóvenes con respecto a la participación social y política, entre las que se cuentan, "una tendencia al descredito de las instituciones políticas y del sistema democrático por parte de los jóvenes", también "una tendencia a que los jóvenes, si bien afirman una creciente preocupación y conciencia por temas emergentes, no traducen esta conciencia en niveles significativos de participación", algo que puede ser explicado por lo antes discutido. Otra tendencia destacable es la que se relaciona "con el ejercicio de la ciudadanía en redes virtuales", y finalmente una tendencia que habla de la "participación en grupos de voluntariado".

El Programa de las Naciones Unidas para el Desarrollo junto a otras instituciones (CIEPLAN, 2008) realizaron un completo estudio sobre los partidos políticos y el sistema electoral en Chile, el cual incluye aspectos relativos a la democracia, partidos políticos y sistema electoral. En aspectos relativos a la confianza de los entrevistados en las instituciones, el congreso y los partidos políticos aparecen en el penúltimo y último lugar respectivamente (15 y 16). Además, el $53 \%$ de los entrevistados no se identifica con ningún partido político. Por otra parte, el $78 \%$ de los jóvenes entrevistados entre 18 y 24 años declara no estar inscrito en los registros electorales, argumentando principalmente que no les interesa, que no abordan los problemas importantes de las personas y que no son honestos; mientras que el $83 \%$ de ellos señala que el voto debiera ser voluntario. El $62 \%$ del total de entrevistados no está nada interesado en política y un $78 \%$ dice no encontrarles ninguna virtud. Entre sus principales defectos está el privilegiar sus intereses personales, las peleas y divisiones, que no representan a la gente y que facilitan la corrupción. Al consultarles sobre qué es lo que debieran hacer los partidos políticos para ganarse su confianza, se propone conectarse con los problemas de la gente, centrar las discusiones en temas importantes para el país y no en peleas personales, presentar propuestas de cambio y sancionar con fuerza en caso de que un miembro se involucre en actos ilegales.

Con base en los datos de la Quinta Encuesta del Instituto Nacional de la Juventud (INJUV, 2006), se definió una tipología de jóvenes en función de variables como la importancia asignada a las elecciones y actitudes hacia la política. Esta construcción tipológica arrojó tres grupos de jóvenes. El primer grupo son los "insatisfechos con el sistema democrático", representan al $22 \%$ y se caracterizan por darle una bajísima importancia a la acción de votar. Este grupo está compuesto principalmente por jóvenes con un nivel educacional secundario y pertenecientes al nivel socioeconómico bajo. Los jóvenes de este grupo no consideran preferible la democracia a otra forma de gobierno, se encuentran insatisfechos con el funcionamiento de la democracia, no están inscritos en los registros electorales y no creen en el voto como instrumento de cambios. El segundo grupo son los de "satisfacción media con el sistema democrático", representan un $33 \%$ y se caracterizan por darle una relativa importancia a la acción de votar. Este grupo también está compuesto por jóvenes con un nivel educacional secundario y de nivel socioeconómico bajo. Se diferencia del grupo anterior por expresar una posición más moderada en el resto de las variables políticas. Y el tercer grupo son los "satisfechos con el sistema democrático", representan a un $45 \%$ y se definen por otorgarle mayor importancia o importancia alta a la acción de votar. Este grupo está compuesto por jóvenes con mayor nivel educacional y un nivel socioeconómico más alto. Los jóvenes de este grupo muestran altos niveles de satisfacción con el sistema democrático y creen en el derecho al voto de los ciudadanos.

En función de lo anterior, se desprende que el nivel de formación educacional de los jóvenes se relaciona en forma directa con la actitud que tienen hacia el sistema político. Es de esperar que se presente una mayor participación política dentro los jóvenes con estudios universitarios. Esto porque las universidades son instituciones que favorecen la 
discusión de temas de interés nacional, y donde los jóvenes pueden encontrar acogida a sus diferentes perspectivas, pensamientos y creencias.

Al parecer, en la Unión Europea, este fenómeno de la baja participación e interés de los jóvenes en política, se asemeja mucho a lo que ocurre en países como Chile. Bendit (2000) plantea que en el proceso de "envejecimiento" de los partidos políticos pudiese estar explicando el rechazo de los jóvenes a incorporarse a la política, lo cual no significa que no tengan interés. En este sentido, Bendit (2000) plantea que han surgido nuevos espacios de reunión de los jóvenes, con fines políticos y otros. El mismo autor plantea:

Una característica de la generación de jóvenes y adultos jóvenes actuales es la articulación de un sentimiento de compromiso social y político "frenado": estando, en principio, dispuestos a comprometerse social y políticamente, la mayoría de los jóvenes considera que les faltan organizaciones y estructuras que consideren adecuadas, es decir, con las cuales puedan identificarse y generar cambios efectivos en la sociedad. (Bendit, 2000, p. 51)

En un análisis de la participación política de los jóvenes chilenos realizado por Gabriela Fernández (2000), la autora concluye:

- Para los jóvenes la política no acaba en lo que los actores políticos practican, aun cuando la carga valórica negativa del concepto proviene justamente de un desencanto con la forma en que estos personajes operan. Superado este rechazo, los jóvenes reconocen en la política algo necesario para el país, en la medida en que se relaciona con el orden administrativo y la capacidad de crecimiento.

- Los jóvenes reconocen en el voto un medio de participación y expresión, pero que es poco efectivo en la práctica, pues no les reporta beneficios personales ni es capaz de producir cambios a nivel nacional.

- Una de las formas recurrentes que utilizan los jóvenes para señalar que el voto no tiene sentido es mencionando el hecho de que los políticos que resultan elegidos finalmente no representan ni cumplen con lo que prometieron durante el periodo de captación de votos.
Respecto a la imagen negativa de los partidos políticos en Chile, el estudio señala que se produce por razones relativas al desencuentro, particularmente por parte de los partidos políticos, con los intereses de los jóvenes. Los mismos partidos reconocen no ser motivadores ni las alternativas más cercanas a los jóvenes.

Alvarado, Ospina, Botero y Muñoz (2008) plantean que la formación ciudadana (socialización política) de los jóvenes tiene que articularse con base en procesos de autorreflexión sobre: la conformación de confianza social; la puesta en marcha de las normas de reciprocidad que superen la discriminación y la desigualdad; y, por último, la construcción de redes de acción social y política que ofrezcan escenarios y oportunidades en los que los jóvenes puedan desplegar su subjetividad política, como ciudadanos plenos. En los procesos de socialización política se requieren paradigmas que rompan el miedo, la apatía, la incredulidad y el escepticismo frente a la posibilidad de pensar futuros, para construir futuros, por parte de los agentes socializadores, pero también de los y las jóvenes (Alvarado et al., 2008).

Desde un punto de vista un poco más actual, Martínez, Silva y Hernández (2010) se refieren a los jóvenes y su rol fundamental a la hora de renovar la sociedad en su conjunto, debido a que ellos son los que tomarán la dirección del país. Además hablan de cómo la generación actual de jóvenes es diferente a las anteriores, ya que estas últimas estuvieron influenciadas por el régimen militar presente en Chile durante 1973-1990.

Los autores, haciendo un análisis de otros estudios, señalan que, quizás debido a lo antes dicho, las expectativas de participación social de los jóvenes no se encaminan por lo tradicional, lo que ha llevado a un aumento en, por ejemplo, movilizaciones, mientras disminuye la participación política convencional.

\section{Personalidad de marca}

\section{Conceptos y modelo}

El concepto de marca se ha venido desarrollando desde hace mucho tiempo atrás asociado a productos o servicios. En este sentido, Hernani (2008) señala que la utilización de las marcas existe desde hace siglos, por 
cuanto inicialmente fueron usadas para diferenciar los productos ofrecidos por diferentes fabricantes. De acuerdo al autor, con el desarrollo del comercio la marca fue asociada con la calidad y confiabilidad ofrecida por los productores. Es así, como la marca ha sido utilizada por los compradores como una guía en la toma de decisiones (Blackett y Harrison, 2001).

Teóricamente, la marca se puede definir como un nombre y/o señal cuya finalidad es identificar el producto de un vendedor o grupo de vendedores, para diferenciarlo de los productos rivales (Stanton, Etzel y Walker, 2000). También el concepto de marca puede entenderse como la representación de lo que el consumidor entiende por la garantía de que el producto que recibe es confiable, bueno para usar y consumir (Gallo, 2000). En este contexto, la marca se ha consolidado como un elemento de valor para los consumidores y productores (Aaker, 1992; Keller, 1993).

La marca tiene una relación estrecha con los consumidores, razón por la cual algunos investigadores le han asignado, al igual que al ser humano, dimensiones de personalidad y emocionalidad (Haigood, 2001). En este sentido, Saavedra, Colmenares y Pirela (2007) señalan que la base de esta afirmación radica en que la relación de un consumidor y una marca específica es muy parecida a una relación entre dos personas. En razón de esto, surge el concepto de personalidad de marca, definida como el conjunto de características humanas asociadas a una marca (Aaker, 1997), o como el modo por el cual un consumidor percibe la marca en dimensiones que típicamente capturan la personalidad de un individuo (Batra, Donald y Singh, 1993).

Así pues, se argumenta que las marcas no suelen ser percibidas únicamente por sus beneficios funcionales, sino también por características de personalidad (Lenk, Batra y Wedel, 2003). Asimismo, se sostiene que la personalidad de marca es un concepto reciente dentro de la literatura académica (Pirela, Villavicencio y Saavedra, 2004) y que ha generado un cambio en la forma de entender cómo los consumidores establecen sus preferencias hacia una marca (Aaker, 1996). Lo anterior implica que la marca y la personalidad prestan una función simbólica o de autoexpresión para el individuo, convirtiéndose en la manera en la que perciben a los demás y a sí mismos (Keller, 1993).

Por otra parte, Saavedra, Urdaneta, Pirela y Colmenares (2008) señalan que el estudio de la medición de la personalidad de la marca y el análisis de un modelo para su medición han sido analizados en los últimos 20 años (Batra, Lenk y Wedel, 2005). De acuerdo a estos autores, el primer modelo de personalidad de marca fue desarrollado por Allen y Olson (1995), quienes usaron el método de discurso narrativo. Asimismo, Saavedra et al. (2008) argumentan que posteriormente Caprara, Barbaranelli y Guido (1997) estudiaron la personalidad de marca utilizando el análisis de metáforas en un esquema lexicográfico. Sin embargo, estos autores señalan que es Aaker (1997) quien desarrolla una escala generalizable para medir la personalidad de marca (Koebel y Ladwein, 1999).

Los investigadores Toldos y Castro (2013) explican que el concepto de la personalidad de marca ha sido ampliamente estudiado debido al poder que este aspecto le concede a la marca. En específico, plantean que "los consumidores tienden a tomar las decisiones de compra basadas en la imagen que éstos forman en sus mentes de las marcas, más que por los atributos o características del producto por sí solo”. En esta misma línea, Toldos (2012) señala que "los consumidores tienden a buscar productos o marcas cuya significancia cultural corresponda a las personas que ellos son o que les gustaría ser, para mantener o establecer un rol social".

En sus investigaciones, Aaker (1997) determinó que los consumidores estadounidenses perciben cinco dimensiones de personalidad en las marcas, cada una conformada por un conjunto de rasgos distintivos: sinceridad, emoción, competencia, sofisticación y rudeza. Según Pirela et al. (2004) las conclusiones de este estudio son importantes, por cuanto Aaker (1997) afirma que todas las marcas comercializadas en Estados Unidos van a ser analizadas y seleccionadas por los consumidores a través de estas cinco dimensiones y los rasgos de personalidad que las componen (figura 1). 
Figura 1. Modelo de personalidad de marca de Aaker (1997).

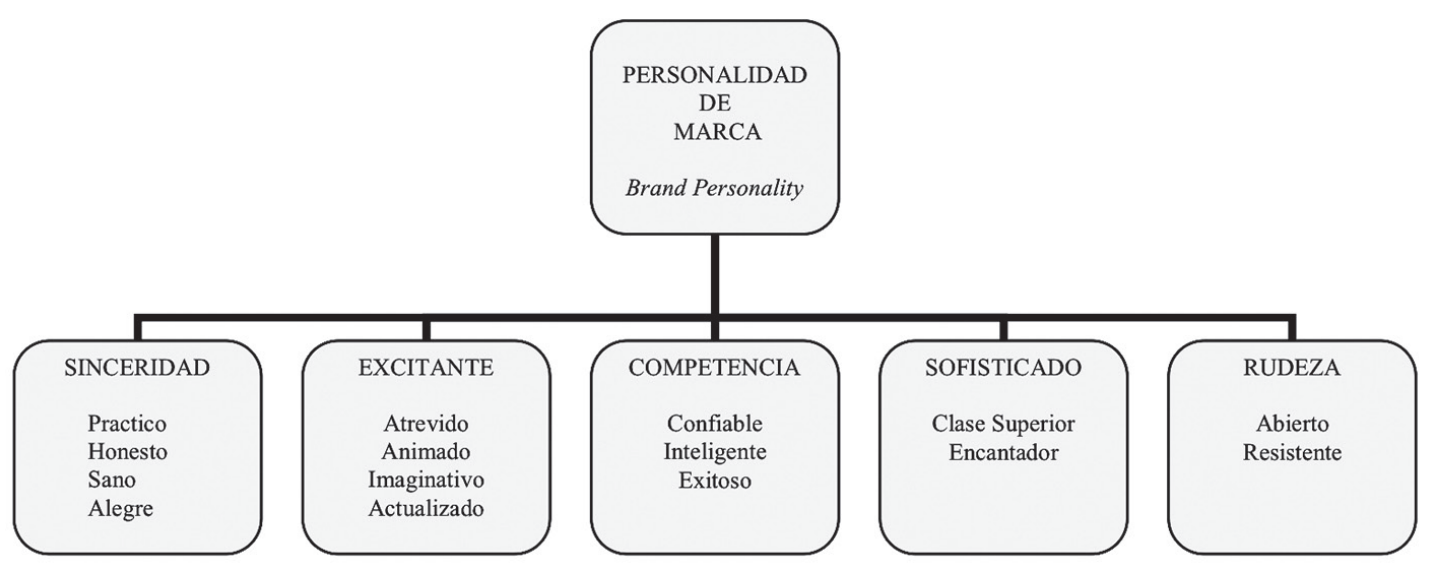

Fuente: Aaker, 1997.

A pesar del reconocimiento que la literatura ha otorgado a la metodología de Aaker (1997), este modelo no está exento de críticas. Austin, Siguaw y Mattila (2003) señalan que el modelo de Aaker (1997) no puede ser replicado en otros países y en otros sectores industriales, especialmente cuando es usado para medir diferencias de personalidad de marca dentro de una categoría específica. Por otra parte, Colmenares y Saavedra (2008) señalan que algunos ítems de la escala de personalidad de marca de Aaker (1997) capturan características más bien funcionales de los productos que de personalidad de marca. Asimismo, Pirela et al. (2004) señalan que las diferencias que se observan entre el estudio original de Aaker (1997) y los estudios posteriores se manifiestan en la selección de los rasgos de personalidad.

\section{Estudios sobre personalidad de marca}

Desde que se desarrolló el concepto de personalidad de marca hace casi dos décadas, se han realizado numerosos estudios aplicados a diversos ámbitos y en múltiples países, intentando determinar los aspectos de personalidad de marca que los individuos perciben de ellas.

En la siguiente tabla (tabla 1), se detallan algunos de estos estudios que se han realizado entre los años 1997 y 2013, observándose un incremento de los estudios a partir del año 2008, los que han incluido países tan diversos como Estados Unidos, China, Japón, Venezuela, Turquía, India, México, España,
Chile, entre otros. Asimismo, el ámbito de aplicación de los estudios ha sido diverso, desde aerolíneas, sector automotriz, farmacias, celulares, marcas corporativas, marcas de lujo, etc. Incluso el concepto ha sido llevado a marca país. Rojas-Méndez (2007) en su presentación "La personalidad de la marca-país como eje para el desarrollo de ventajas competitivas" destaca cómo esta marca país influye en diferentes aspectos del desarrollo de un país. Sin embargo, en el ámbito de partidos políticos no se tiene referencia de estudios que se hayan realizado con personalidad de marca, por lo cual resulta de interés los resultados de esta investigación que aportan en esa línea.

Por otra parte, es interesante observar cómo las dimensiones utilizadas han sido modificadas con relación a las originales desarrolladas por Aaker (1997), variando también en cantidad (desde un mínimo de tres hasta un máximo de diez).

Con relación al tema de la participación y la confianza en los partidos políticos, este estudio puede aportar con una dimensión más emocional de la percepción que tienen los jóvenes sobre los partidos políticos. Esto porque la teoría de personalidad de marca puede ser de utilidad para entender la decisión de los jóvenes de automarginarse del sistema político. A través de la teoría de personalidad de marca se pueden estudiar los rasgos de personalidad que los jóvenes atribuyen a los partidos políticos. Esta perspectiva teórica es relevante, por cuanto los jóvenes no manifiestan una opinión positiva sobre 
los partidos políticos. Dado esto, los partidos políticos pueden usar la teoría de personalidad de marca para conocer el posicionamiento que tienen dentro de la ciudadanía, y en especial en aquellos grupos de la población que se sienten menos identificados con el sistema político.

Tabla 1. Dimensiones de personalidad de marca en diversos países y ámbitos

\begin{tabular}{|c|c|c|c|c|}
\hline Autores & País aplicación & $\begin{array}{l}\text { Ámbito de } \\
\text { aplicación }\end{array}$ & $\begin{array}{c}\mathbf{n}^{\circ} \\
\text { dimensiones }\end{array}$ & $\begin{array}{c}\text { Dimensiones } \\
\text { personalidad de marca }\end{array}$ \\
\hline Aaker (1997) & EE. UU. & $\begin{array}{l}\text { Desarrollo Escala } \\
\text { de Aaker validación } \\
\text { EE. UU. }\end{array}$ & 5 & $\begin{array}{l}\text { Sinceridad, emoción, competencia, } \\
\text { sofisticación y rudeza. }\end{array}$ \\
\hline $\begin{array}{l}\text { Barrios y Masa } \\
\text { (1999) }\end{array}$ & Venezuela & $\begin{array}{l}\text { Validación Escala } \\
\text { Aaker en Venezuela }\end{array}$ & 5 & $\begin{array}{l}\text { Sinceridad, emoción, competencia, } \\
\text { sofisticación y rudeza. }\end{array}$ \\
\hline $\begin{array}{l}\text { Koebel y Ladwein } \\
\text { (1999) }\end{array}$ & Francia & $\begin{array}{l}\text { Validación Escala } \\
\text { Aaker en Francia }\end{array}$ & 6 & $\begin{array}{l}\text { Competencia, dominación, reflexión, } \\
\text { masculinidad, expansión y seducción. }\end{array}$ \\
\hline $\begin{array}{l}\text { Aaker, Benet- } \\
\text { Martínez y } \\
\text { Gorolera (2001) }\end{array}$ & Japón & $\begin{array}{l}\text { Validación Es- } \\
\text { cala Aaker en } \\
\text { Japón/España }\end{array}$ & 5 & $\begin{array}{l}\text { Sinceridad, emoción, competencia, } \\
\text { sofisticación y pasividad. }\end{array}$ \\
\hline $\begin{array}{l}\text { Aaker, Benet- } \\
\text { Martínez y } \\
\text { Garolera (2001) }\end{array}$ & España & $\begin{array}{l}\text { Validación Es- } \\
\text { cala Aaker en } \\
\text { España/Japón }\end{array}$ & 5 & $\begin{array}{l}\text { Sinceridad, emoción, competencia, } \\
\text { pasividad y pasión. }\end{array}$ \\
\hline $\begin{array}{l}\text { Álvarez-Ortiz y } \\
\text { Harris (2002) }\end{array}$ & México & $\begin{array}{l}\text { Marcas globales } \\
\text { EE. UU. vs. México }\end{array}$ & 5 & $\begin{array}{l}\text { Sinceridad, emoción, competencia, } \\
\text { sofisticación y género. }\end{array}$ \\
\hline $\begin{array}{l}\text { Muller y Chandon } \\
\text { (2003) }\end{array}$ & Francia & $\begin{array}{l}\text { Impacto de la página } \\
\text { web en la percep- } \\
\text { ción de la pm }\end{array}$ & 3 & Juventud, sinceridad y sofisticación. \\
\hline $\begin{array}{l}\text { Pirela, Villavicencio } \\
\text { y Saavedra (2004) }\end{array}$ & Venezuela & Centros Comerciales & 5 & $\begin{array}{l}\text { Sinceridad, emocionante, } \\
\text { pasional, pasividad y rudeza. }\end{array}$ \\
\hline Lan y Richey (2006) & EE. UU. & Marcas Corporativas & 3 & Corazón, mente y cuerpo. \\
\hline Rojas-Méndez (2007) & Chile & Marca País & 7 & $\begin{array}{l}\text { Economía, turismo, geografía y } \\
\text { naturaleza, gobierno, tecnología, } \\
\text { cultura y sociedad. }\end{array}$ \\
\hline $\begin{array}{l}\text { Saavedra, } \\
\text { Colmenares y } \\
\text { Pirela (2007) }\end{array}$ & Venezuela & $\begin{array}{l}\text { Cadenas de } \\
\text { Farmacias }\end{array}$ & 3 & Emocionante, sinceridad y pasividad. \\
\hline $\begin{array}{l}\text { Saavedra, Pirela y } \\
\text { Colmenares (2008) }\end{array}$ & Venezuela & El Venezolano & 5 & $\begin{array}{l}\text { Sinceridad, emoción, pasión, } \\
\text { pasividad y rudeza. }\end{array}$ \\
\hline $\begin{array}{l}\text { Schlesinger y } \\
\text { Cervera (2008) }\end{array}$ & España & Compañías Aéreas & 4 & $\begin{array}{l}\text { Sinceridad, competencia, } \\
\text { emocionante y sofisticado. }\end{array}$ \\
\hline $\begin{array}{l}\text { Saavedra, } \\
\text { Urdaneta, Pirela y } \\
\text { Colmenares (2008) }\end{array}$ & Venezuela & Mercado Automotriz & 4 & $\begin{array}{l}\text { Sinceridad, pacífico, emocionante } \\
\text { y pasional (apasionado). }\end{array}$ \\
\hline Heere (2010) & Nueva Zelanda & $\begin{array}{l}\text { Nuevo método de } \\
\text { definición pm }\end{array}$ & 10 & $\begin{array}{l}\text { Competitivo, excitante, profesional, } \\
\text { dinámico, apasionante, orgulloso, } \\
\text { accesible, cálido, frio, atractivo. }\end{array}$ \\
\hline $\begin{array}{l}\text { Olavarrieta, } \\
\text { Friedmann y } \\
\text { Manzur (2010) }\end{array}$ & Chile & $\begin{array}{l}\text { Marcas en distin- } \\
\text { tos sectores }\end{array}$ & 6 & $\begin{array}{l}\text { Sofisticación, competencia, rudeza, } \\
\text { excitante, tradicional, sinceridad. }\end{array}$ \\
\hline
\end{tabular}


Universidad Pedagógica Nacional

Facultad de Humanidades

\begin{tabular}{|c|c|c|c|c|}
\hline $\begin{array}{l}\text { Freling, Crosno y } \\
\text { Henard (2011) }\end{array}$ & EE. UU. & $\begin{array}{l}\text { Investigación } \\
\text { Empírica }\end{array}$ & 3 & Favorabilidad, originalidad, claridad. \\
\hline Akin (2011) & Turquía & Teléfonos Celulares & 4 & $\begin{array}{l}\text { Competencia, emoción, } \\
\text { tradicionalismo, "androgen". }\end{array}$ \\
\hline Toldos (2012) & México & $\begin{array}{l}\text { Laptops, Sham- } \\
\text { poo, Perfumes }\end{array}$ & 7 & $\begin{array}{l}\text { Éxito, vivacidad, sofisticación, } \\
\text { sinceridad, emocionalidad, } \\
\text { rudeza, profesionalismo. }\end{array}$ \\
\hline $\begin{array}{l}\text { Jie, Chou y } \\
\text { Chou (2012) }\end{array}$ & China & $\begin{array}{l}\text { Comparación escalas } \\
\text { de Japón y EE. UU. }\end{array}$ & 6 & $\begin{array}{l}\text { Sinceridad, emoción, competencia, } \\
\text { sofisticación, pasividad, rudeza. }\end{array}$ \\
\hline $\begin{array}{l}\text { Muller y Zancan } \\
\text { (2012) }\end{array}$ & Brasil & $\begin{array}{l}\text { Validación esca- } \\
\text { la Aaker (1997) } \\
\text { en Brasil }\end{array}$ & 5 & $\begin{array}{l}\text { Credibilidad, placer, audacia, } \\
\text { sofisticación, sensibilidad. }\end{array}$ \\
\hline Nguyen (2013) & Suiza & $\begin{array}{l}\text { Organizaciones sin } \\
\text { fines de lucro }\end{array}$ & 7 & $\begin{array}{l}\text { Integridad, humano, sofisticación, } \\
\text { rudeza, sociabilidad, ecuánime, } \\
\text { trabajador especializado. }\end{array}$ \\
\hline $\begin{array}{l}\text { Schlesinger, Cervera } \\
\text { y Yagüe (2013) }\end{array}$ & España & Compañías Aéreas & 4 & $\begin{array}{l}\text { Sinceridad, competencia, } \\
\text { emocionante, sofisticado. }\end{array}$ \\
\hline $\begin{array}{l}\text { Toldos y Castro } \\
\text { (2013) }\end{array}$ & México y Brasil & Marcas de Lujo & 7 & $\begin{array}{l}\text { Éxito/sofisticación, sinceridad/ } \\
\text { emotividad, emocionante, apertura } \\
\text { a la experiencia, competencia, } \\
\text { trabajadora, género. }\end{array}$ \\
\hline
\end{tabular}

Fuente: Elaboración propia.

\section{Metodología}

La presente investigación es de tipo concluyente descriptiva con corte transversal o seccional (Malhotra, 2004). El objetivo de la presente investigación es proponer un modelo teórico sobre la personalidad de marca de los partidos políticos. Para esto, se desarrolla un cuestionario (escala), que se compone del conjunto de rasgos de personalidad que caracterizan a los partidos políticos. No se realiza la validación psicométrica del modelo a través de la aplicación de ecuaciones estructurales. No obstante, se complementa el análisis de validez de contenido, con la realización de un pretest. Con el pretest se realiza una evaluación previa de la significancia estadística del modelo propuesto (validez convergente y validez divergente). Además, se busca mejorar la calidad del estudio estadístico previo, con el análisis de unidimensionalidad de las escalas (dimensiones) que componen el modelo.

\section{Selección de la muestra}

La educación superior en Chile se encuentra concentrada en la Región Metropolitana (Araya-Castillo, 2009). Esto porque un $71,7 \%$ de las universidades chilenas tienen sedes en la Región Metropolitana. Además, del total de matricula de alumnos que cursaban estudios de pregrado al año 2005, un $55 \%$ se concentraba en la Región Metropolitana (Brunner y Uribe, 2007). Por ello, el marco muestral se encuentra compuesto por estudiantes universitarios de la Región Metropolitana.

Solo se consideraron estudiantes universitarios debido a que la matrícula de estudios superiores en Chile se concentra en las universidades. $\mathrm{Al}$ año 2007 un $68,3 \%$ de las personas que estudiaban estudios superiores y un $67,4 \%$ de las que cursaban programas de pregrado lo realizaban en alguna de las 60 universidades existentes en el país (Araya-Castillo, 2009). 
El tamaño muestral del pretest está compuesto por 204 encuestas válidas. El tipo de muestreo aplicado fue no probabilístico por conveniencia (Malhotra, 2004), ya que la muestra fue aplicada en universidades de la Región Metropolitana en las que los encuestadores tenían autorización para llevar a cabo la recolección de información. La recolección de datos fue realizada durante los meses de abril y mayo del año 2009. A fines del 2009 se realizaron las elecciones parlamentarias y presidenciales.

\section{Composición de la muestra}

Un $56,4 \%$ de los encuestados fueron hombres y un $43,6 \%$ mujeres. La edad promedio de los encuestados fue de 24,1 años, siendo los mínimo y máximo de 18 y 29 años, respectivamente. Esto es congruente con la clasificación que hace el Instituto Nacional de la Juventud (INJUV), por cuanto considera dentro del grupo de jóvenes a las personas que tienen entre 18 y 29 años.

Por otra parte, un 33,8\% de los encuestados estudia carreras del área de economía y negocios, un $29,4 \%$ del área de ciencias sociales y derecho, un 22,6\% del área de la salud y un 14,2\% del área de ingenierías técnicas. Además, un 31,4 \% de los encuestados estudia en una universidad estatal, un $15,7 \%$ en una universidad particular con aporte del estado y un 52,9 \% en una universidad privada.

La opinión de los jóvenes universitarios es representativa solo de un segmento particular de la población. No obstante su estudio es importante, por cuanto representan a la población de jóvenes que en teoría deberían tener un mayor nivel de opinión e interés sobre la política (Araya-Castillo y Etchebarne, 2009). Además, concentrar la muestra en un conjunto de jóvenes con características similares permite controlar el posible sesgo derivado del error muestral (error de respuesta). Esto es importante en la etapa de elaboración de un instrumento, por cuanto el interés se encuentra focalizado en la agrupación de las variables y no en la connotación positiva o negativa de las respuestas.

Del total de jóvenes que componen la muestra, un $62,4 \%$ se encuentra inscrito en los registros elec- torales. A la fecha del estudio, la inscripción en los registros electorales era voluntaria, razón por la cual se puede argumentar que estas personas participan activamente (o por lo menos en forma regular) en los procesos eleccionarios (es decir, participan en política). Este porcentaje difiere de la cifra a nivel nacional, en donde se señala que en el año 2008 solo un $32 \%$ de los sujetos jóvenes entre 18 y 29 años de edad se encontraba inscrito en los registros electorales. Según la Quinta Encuesta Nacional de la Juventud (INJUV, 2006), la inscripción en los registros electorales es más frecuente entre los varones, los sujetos jóvenes entre 25 y 29 años de edad, y los de nivel socioeconómico ABC1 (es decir, de mayores ingresos). Por el contrario, no inscribirse es más común entre las mujeres, los sujetos jóvenes de 18 a 19 años de edad, las personas de niveles socioeconómicos más bajos ( $\mathrm{C} 3, \mathrm{D}$ y E), los residentes en sectores rurales y quienes no estudian ni trabajan, con lo cual el padrón electoral no solo envejece, sino que también se "elitiza".

\section{Significancia estadística}

La confiabilidad de una medida analiza si esta se halla libre de errores aleatorios y, en consecuencia, proporciona resultados estables y consistentes (Sánchez y Sarabia, 1999). La confiabilidad es una condición necesaria, aunque no suficiente, para la validez de dicha medida. La validez de una medida analiza si el instrumento utilizado mide lo que el investigador pretende medir, es decir, estudia el error sistemático: a menor error sistemático, mayor validez de la medida (Capelleras y Veciana, 2001).

La validez tiene tres aspectos: validez de contenido, validez divergente y validez convergente (Nunnally, 1978, 1987). La validez de contenido se refiere al grado en el que la medida recoge el dominio del concepto estudiado. La validez divergente se refiere al grado de eficacia con el que se puede pronosticar una variable a partir de la medición efectuada. La validez convergente significa que un mismo fenómeno medido de diversas formas independientes da lugar a resultados similares. 
En una perspectiva similar, Owlia y Aspinwall (1998) señalan que la validez comprende dos aspectos, los cuales son la validez cualitativa y la validez cuantitativa. La primera determina si las medidas capturan los factores claves de un constructo no observable. La segunda se basa principalmente en la investigación de la correlación existente entre las variables. En razón de lo anterior, es posible señalar que a través del cumplimiento de la validez divergente y convergente, se logra al mismo tiempo responder al criterio de validez cuantitativa.

Finalmente, es necesario verificar que cada una de las escalas (dimensiones) presenta suficientes grados de unidimensionalidad, lo cual implica que mide un único constructo. Con el objeto de identificar aquellos indicadores que menos están adheridos a un determinado factor, se aplican análisis factoriales de componentes principales (análisis factorial exploratorio) con rotación varimax en cada una de las escalas (Hair, Black, Babin, Anderson y Tatham, 2005).

\section{Etapas de elaboración del modelo}

En la presente investigación se siguen diversos procedimientos que permiten dar cumplimiento a los requisitos de validez y confiabilidad. La validez de contenido se consigue con la revisión de la literatura, investigación exploratoria y la opinión de expertos (Deng y Dart, 1994). Con esto se obtienen las dimensiones y rasgos de personalidad que deberían ser parte del modelo de personalidad de marca de los partidos políticos.

Los estudios que proponen modelos teóricos se enfocan en garantizar la validez de contenido (validez cualitativa) de la escala de medida. No obstante, en la presente investigación se propone realizar un pretest, por cuanto esto permite tener una primera aproximación de la adecuación estadística de la escala propuesta (Torres y Araya-Castillo, 2010). Esto permite evaluar la validez convergente y divergente (validez cuantitativa) del modelo propuesto y propone complementar su estudio estadístico con el análisis de unidimensionalidad de las escalas (dimensiones) que lo componen.
En razón de lo anterior, la escala (modelo) propuesta se aplicó a una muestra representativa del grupo de estudio. Con la información recolectada se aplicó el análisis factorial de componentes principales con rotación varimax (Hair et al., 2005). Este análisis permitió obtener las dimensiones de personalidad en función de las cuales los jóvenes universitarios definen a los partidos políticos. Sin embargo, aun cuando el análisis de componentes principales sea apropiado, esto no garantiza que los resultados obtenidos sean estadísticamente significativos. No obstante, se analizó la validez y confiabilidad de las dimensiones estratégicas (Nunnally, 1978, 1987).

La validez divergente se analiza a través del análisis de correlación entre los factores obtenidos, por cuanto se buscan correlaciones nulas (García y Ruiz, 2007). Y la validez convergente se analiza a través del análisis de correlación entre la escala de medida y otra escala, por cuanto se busca que haya correlación entre dos variables distintas del mismo fenómeno (Capelleras y Veciana, 2001).

Para valorar la confiabilidad de una dimensión compuesta por tres o más variables se calcula el coeficiente alfa de Cronbach, cuyo valor mínimo aconsejable para un análisis confirmatorio es de 0,7 ; cuando el análisis es de tipo exploratorio, el mínimo recomendado es de 0,6 . Por otra parte, para determinar la confiabilidad de dimensiones compuestas por dos variables se aplica el análisis de correlación; los valores obtenidos para las correlaciones deben ser significativos al $99 \%$ o $95 \%$ de confianza (Hair, Anderson, Tatham y Black, 1998).

Para terminar, cada una de las subescalas presentan un buen grado de unidimensionalidad cuando los ítems presentan cargas factoriales superiores a 0,4 (Larwood, Falbe, Kriger y Miesing, 1995). Además, los ítems deben cargar sobre un único factor y se deben presentar adecuados niveles de varianza explicada, kmo y test de esfericidad de Bartlett (Hair et al., 2005). Cuando uno o más indicadores cargan en más de un factor se deben ir eliminando hasta conseguir la unidimensionalidad. 


\section{Propuesta de modelo}

En la etapa de elaboración del instrumento de medición es relevante la validez de contenido (Deng y Dart, 1994), por cuanto es una señal de que los indicadores incluidos en la encuesta son una muestra representativa del conjunto que podría haber sido utilizado. Dado esto, se realizó una revisión del conjunto de rasgos de personalidad considerados por los autores en investigaciones previas. Con este procedimiento se conocen los rasgos de personalidad que son utilizados por los investigadores en estudios aplicados en diferentes sectores industriales y culturales.

La revisión de la literatura permite sostener que el número de rasgos considerados en los estudios previos de personalidad de marca no es uniforme. Los trabajos que han replicado el modelo de per- sonalidad de marca de Aaker (1997) presentan un número similar de rasgos, pero aquellos que han creado y validado una escala diferente varían en el número de ítems. Además, es posible argumentar que la teoría de personalidad de marca no ha sido aplicada en el estudio de los partidos políticos (Araya-Castillo y Etchebarne, 2009).

Considerando lo anterior, se buscó comparar los rasgos de personalidad incluidos en estudios previos (realizados en otros sectores), con los considerados como relevantes en el análisis de los partidos políticos. Para esto, se aplicó un cuestionario semiestructurado a integrantes del grupo de estudio. Se le solicitó a 103 jóvenes universitarios que escribieran en una hoja los rasgos de personalidad que ellos piensan caracterizan a los partidos políticos chilenos, resultados que se presentan en la tabla 2. En la primera columna se propone el concepto que

Tabla 2. Rasgos de personalidad de partidos políticos en Chile

\begin{tabular}{|c|c|c|c|}
\hline $\begin{array}{l}\text { Rasgo de } \\
\text { personalidad }\end{array}$ & Rasgos de personalidad similares & $\begin{array}{l}\text { Frecuencia } \\
\text { absoluta }\end{array}$ & $\begin{array}{l}\text { Frecuencia } \\
\text { relativa (\%) }\end{array}$ \\
\hline Corruptos & $\begin{array}{l}\text { Poco éticos, deshonestos, ladrones, inmorales, poco } \\
\text { transparentes, descarados, vendidos, aprovechadores, } \\
\text { corruptos, desleales, coimeros, turbios, sinvergüenzas, } \\
\text { mafiosos, manipuladores, maquiavélicos, engañadores, } \\
\text { chaqueteros, barreros, falsos, hipócritas, poco creíbles, } \\
\text { apitutados, confusos, interesados y doble estándar. }\end{array}$ & 136 & 26,15 \\
\hline Ambiciosos & $\begin{array}{l}\text { Egoístas, individualistas, avaros, con ansias de poder, arribistas, } \\
\text { piensan en el bien propio, competitivos, avasalladores, } \\
\text { interesados, oportunistas, egocéntricos y ambiciosos. }\end{array}$ & 69 & 13,27 \\
\hline Mentirosos & $\begin{array}{l}\text { Manipuladores, no fiables, incumplidores, inconsecuentes, } \\
\text { prometedores, sinceros, demagogos, chamullentos, } \\
\text { mentirosos, cínicos, charlatanes y populistas. }\end{array}$ & 64 & 12,31 \\
\hline Innovadores & $\begin{array}{l}\text { Serios, tradicionales, conservadores, retrógrados, } \\
\text { formales, anticuados, desordenados, fomes, } \\
\text { aburridos, cerrados, progresistas, inflexibles, poco } \\
\text { originales, poco innovadores y poco creativos. }\end{array}$ & 43 & 8,27 \\
\hline Polémicos & $\begin{array}{l}\text { Divisores, peleadores, agresivos, camorreros, alterados, } \\
\text { conflictivos, descalificadores, confrontacionales, } \\
\text { sumisos, irrespetuosos, extremistas e intolerantes. }\end{array}$ & 43 & 8,27 \\
\hline Elitistas & Clasistas, discriminadores, segmentadores, racistas y machistas. & 31 & 5,96 \\
\hline Competentes & $\begin{array}{l}\text { Ineficientes, lentos, burocráticos, incompetentes, } \\
\text { irresponsables y poco competentes. }\end{array}$ & 30 & 5,77 \\
\hline Comprometidos & Sociables, comprometidos y representativos de la sociedad. & 25 & 4,81 \\
\hline
\end{tabular}


Universidad Pedagógica Nacional

Facultad de Humanidades

\begin{tabular}{|c|c|c|c|}
\hline Serviciales & $\begin{array}{l}\text { Poco participativos, poco serviciales, acogedores, } \\
\text { sensibles y poco preocupados. }\end{array}$ & 20 & 3,85 \\
\hline Viejos & Antiguos, viejos y avejentados. & 18 & 3,46 \\
\hline Sofisticados & $\begin{array}{l}\text { Incultos, estudiosos, intelectuales, ignorantes, } \\
\text { mal preparados, astutos, inteligentes, poco } \\
\text { importantes, no respetados y mediocres. }\end{array}$ & 18 & 3,46 \\
\hline Prácticos & $\begin{array}{l}\text { Concretos, directos, no concretan las ideas, } \\
\text { utópicos, idealistas y realistas. }\end{array}$ & 12 & 2,31 \\
\hline Entusiastas & Conformistas, fuertes, positivos y motivadores. & 11 & 2,12 \\
\hline
\end{tabular}

Fuente: Elaboración propia.

resume un conjunto de características similares. Esto porque los estudiantes universitarios expresan en forma diversa su percepción sobre los rasgos de personalidad que caracterizan a los partidos políticos.

La escala propuesta fue depurada a través de un análisis exhaustivo recomendado por De Wulf y Odekerken-Schrode (2003). Con este objetivo se hizo uso de herramientas cualitativas, por cuanto permiten analizar los fenómenos con un mayor grado de profundidad de lo que es posible con las herramientas cuantitativas (Denzin y Lincoln, 2000). Específicamente las herramientas cualitativas usadas son las de entrevistas en profundidad y grupos focales.

Se realizaron 4 grupos focales con jóvenes universitarios (en total 36 jóvenes universitarios). El grupo focal permite poner el acento en el grupo de estudio, dado que son los propios participantes quienes construyen la dinámica de la reunión y de esta forma se minimiza el sesgo probable de influenciar las respuestas (Araya-Castillo y Pedreros-Gajardo, 2013). Por lo tanto, emplear grupos focales nos permitió estudiar y analizar a los sujetos jóvenes en un proceso de interacción, lo cual es relevante para conocer el posicionamiento que tienen los partidos políticos dentro de nuestro grupo de estudio.

Junto con esto, se realizaron 12 entrevistas en profundidad del tipo semiestructuradas. Las entrevistas individuales (del tipo semiestructuradas) permiten acceder a información que no es posible con los grupos focales, ya sea por el corto tiempo que tiene cada persona para expresar sus ideas y/o porque puede existir una presión social que conduzca a acuerdos sociales en las respuestas (ArayaCastillo y Pedreros-Gajardo, 2013). Es así como las entrevistas individuales nos permitieron acceder a una alta intensidad en los pensamientos, sentimientos, percepciones, ideas y creencias de los jóvenes universitarios sobre los rasgos de personalidad que caracterizan a los partidos políticos.

Además, se contó con la participación de 6 expertos en el tema de estudio. Por una parte, se seleccionaron 3 expertos con conocimientos y experiencia de investigación en temas de sociología, ciencias políticas y psicología social. Los otros 3 expertos que se seleccionaron tienen conocimiento y experiencia de investigación en temas de personalidad de marca y marketing político. Se solicitó a estos expertos que proporcionaran su retroalimentación sobre la escala propuesta. Este procedimiento se considera como validez de experto y es parte de la validez de contenido. Asimismo, con 2 de estos expertos (uno de cada grupo) se realizaron entrevistas en profundidad con el objetivo de conocer con un mayor nivel de profundidad la percepción de los jóvenes sobre los partidos políticos.

Con este procedimiento se obtuvieron 47 rasgos de la personalidad de marca que definen a los partidos políticos chilenos. Estos rasgos se han agrupado en 10 dimensiones de personalidad de marca (tabla 3). El proceso de generación de los rasgos de personalidad, y su posterior agrupación en dimensiones, es subjetivo por naturaleza. Dado esto, en la presente investigación se ha buscado reducir el sesgo de los investigadores a través de la revisión de la literatura, por cuanto se consideraron los rasgos de personalidad utilizados con mayor frecuencia en la bibliografía. Además, en la elaboración del modelo se consideró la opinión de los jóvenes universitarios y la retroalimentación de expertos en el tema de estudio. 
Tabla 3. Dimensiones personalidad de marca de partidos políticos en Chile

\begin{tabular}{|c|c|c|c|c|c|}
\hline Dimensiones & Sinceridad & Servicial & Innovación & Estimulante & Tradicional \\
\hline $\begin{array}{l}\text { Rasgos de } \\
\text { personalidad }\end{array}$ & $\begin{array}{c}\text { Honestos } \\
\text { Transparentes } \\
\text { Confiables } \\
\text { Éticos } \\
\text { Genuinos }\end{array}$ & $\begin{array}{c}\text { Serviciales } \\
\text { Preocupados } \\
\text { Generosos } \\
\text { Amigables Com- } \\
\text { prometidos }\end{array}$ & $\begin{array}{c}\text { Original } \\
\text { Creativos } \\
\text { Innovadores } \\
\text { Vanguardistas } \\
\text { Modernos }\end{array}$ & $\begin{array}{l}\text { Juveniles } \\
\text { Entretenidos } \\
\text { Entusiastas } \\
\text { Motivados } \\
\text { Emocionantes } \\
\text { Apasionados }\end{array}$ & $\begin{array}{c}\text { Serios } \\
\text { Conservadores } \\
\text { Tradicionales } \\
\text { Formales }\end{array}$ \\
\hline Dimensiones & Sofisticado & Competencia & Ambición & Rudeza & Elitistas \\
\hline $\begin{array}{l}\text { Rasgos de } \\
\text { personalidad }\end{array}$ & $\begin{array}{l}\text { Glamorosos } \\
\text { Elegantes } \\
\text { Sofisticados }\end{array}$ & $\begin{array}{l}\text { Eficientes } \\
\text { Cumplidores } \\
\text { Competentes } \\
\text { Prácticos } \\
\text { Responsables }\end{array}$ & $\begin{array}{l}\text { Ambiciosos } \\
\text { Individualistas } \\
\text { Oportunistas } \\
\text { Egoístas }\end{array}$ & $\begin{array}{c}\text { Agresivos } \\
\text { Peleadores } \\
\text { Conflictivos } \\
\text { Descalificadores } \\
\text { Intolerantes }\end{array}$ & $\begin{array}{c}\text { Discriminadores } \\
\text { Machistas } \\
\text { Racistas }\end{array}$ \\
\hline
\end{tabular}

Fuente: Elaboración propia.

\section{Resultados}

Con los 47 rasgos de personalidad se desarrolló un cuestionario en una escala likert de 5 puntos (donde 1 = muy poco descriptivo y 5 = muy descriptivo). Se preguntó a los jóvenes universitarios su percepción sobre los rasgos de personalidad que caracterizan a los partidos políticos. Con la información recolectada se aplicó el análisis factorial de componentes principales con rotación varimax (Hair et al., 2005), el cual arrojó las dimensiones que definen la personalidad de marca de los partidos políticos en Chile: 1) sinceridad; 2) ambición; 3) competencia; 4) estimulante; 5) tradicional; 6) sofisticado; 7) rudeza; y 8) elitistas.
En la tabla 4 se puede observar la composición de las dimensiones de personalidad de marca. El nombre asignado a cada una de las dimensiones responde al concepto que agrupa a los diferentes rasgos de personalidad que las componen. Con respecto al modelo inicial, la nueva propuesta disminuye de 10 a 8 las dimensiones de personalidad de marca. Esto porque las dimensiones competencia y servicial se agrupan en una sola dimensión que ha sido denominada competencia. Lo mismo sucede con las dimensiones innovación y estimulante, debido a que ambas se agrupan en una única dimensión que se ha denominado estimulante.

Tabla 4. Determinación dimensiones de personalidad de marca de partidos políticos

\begin{tabular}{|c|c|c|c|c|c|c|}
\hline $\begin{array}{c}\text { Dimensión } \\
\text { de } \\
\text { personalidad }\end{array}$ & Variables & $\begin{array}{c}\text { Cargas } \\
\text { factoriales }\end{array}$ & $\begin{array}{c}\text { Comunalidad } \\
\text { de } \\
\text { extracción }\end{array}$ & Eigenvalues & $\begin{array}{c}\text { Varianza } \\
\text { expli- } \\
\text { cada (\%) }\end{array}$ & $\begin{array}{l}\text { Varianza } \\
\text { acumu- } \\
\text { lada (\%) }\end{array}$ \\
\hline $\begin{array}{c}1 \\
\text { Sinceridad }\end{array}$ & $\begin{array}{l}\text { Honestos } \\
\text { Transparentes } \\
\text { Confiables } \\
\text { Éticos } \\
\text { Genuinos }\end{array}$ & $\begin{array}{l}0,776 \\
0,772 \\
0,741 \\
0,739 \\
0,661\end{array}$ & $\begin{array}{l}0,737 \\
0,735 \\
0,688 \\
0,686 \\
0,585\end{array}$ & 6,709 & 14,275 & 14,275 \\
\hline $\begin{array}{c}2 \\
\text { Ambición }\end{array}$ & $\begin{array}{c}\text { Ambiciosos } \\
\text { Individualistas } \\
\text { Oportunistas } \\
\text { Egoístas }\end{array}$ & $\begin{array}{l}0,698 \\
0,694 \\
0,567 \\
0,452\end{array}$ & $\begin{array}{l}0,744 \\
0,738 \\
0,619 \\
0,606\end{array}$ & 5,101 & 10,854 & 25,130 \\
\hline
\end{tabular}


Universidad Pedagógica Nacional

Facultad de Humanidades

\begin{tabular}{|c|c|c|c|c|c|c|}
\hline $\begin{array}{c}3 \\
\text { Competencia }\end{array}$ & $\begin{array}{c}\text { Eficientes } \\
\text { Cumplidores } \\
\text { Competentes } \\
\text { Prácticos } \\
\text { Responsables } \\
\text { Preocupados } \\
\text { Comprometidos } \\
\text { Serviciales } \\
\text { Generosos } \\
\text { Amigables } \\
\text { Burocráticos }\end{array}$ & $\begin{array}{l}0,832 \\
0,831 \\
0,792 \\
0,791 \\
0,641 \\
0,637 \\
0,612 \\
0,594 \\
0,579 \\
0,525 \\
0,520\end{array}$ & $\begin{array}{l}0,824 \\
0,789 \\
0,750 \\
0,721 \\
0,709 \\
0,688 \\
0,666 \\
0,640 \\
0,639 \\
0,631 \\
0,629\end{array}$ & 4,824 & 10,263 & 35,393 \\
\hline $\begin{array}{c}4 \\
\text { Estimulante }\end{array}$ & $\begin{array}{c}\text { Entretenidos } \\
\text { Apasionados } \\
\text { Originales } \\
\text { Creativos } \\
\text { Innovadores } \\
\text { Vanguardistas } \\
\text { Modernos } \\
\text { Juveniles } \\
\text { Entusiastas } \\
\text { Motivados } \\
\text { Emocionantes }\end{array}$ & $\begin{array}{l}0,821 \\
0,812 \\
0,764 \\
0,702 \\
0,685 \\
0,648 \\
0,646 \\
0,645 \\
0,519 \\
0,440 \\
0,439\end{array}$ & $\begin{array}{l}0,801 \\
0,738 \\
0,728 \\
0,719 \\
0,709 \\
0,708 \\
0,706 \\
0,690 \\
0,654 \\
0,622 \\
0,569\end{array}$ & 4,460 & 9,489 & 44,882 \\
\hline $\begin{array}{c}5 \\
\text { Tradicional }\end{array}$ & $\begin{array}{c}\text { Conservadores, } \\
\text { Tradicionales } \\
\text { Formales } \\
\text { Serios }\end{array}$ & $\begin{array}{l}0,851 \\
0,799 \\
0,701 \\
0,588\end{array}$ & $\begin{array}{l}0,809 \\
0,765 \\
0,750 \\
0,687\end{array}$ & 4,433 & 9,431 & 54,313 \\
\hline $\begin{array}{c}6 \\
\text { Sofisticado }\end{array}$ & $\begin{array}{l}\text { Elegantes } \\
\text { Sofisticados } \\
\text { Glamorosos }\end{array}$ & $\begin{array}{l}0,653 \\
0,644 \\
0,566\end{array}$ & $\begin{array}{l}0,778 \\
0,720 \\
0,712\end{array}$ & 3,134 & 6,669 & 60,982 \\
\hline $\begin{array}{c}7 \\
\text { Rudeza }\end{array}$ & $\begin{array}{c}\text { Agresivos } \\
\text { Peleadores } \\
\text { Conflictivos } \\
\text { Descalificadores } \\
\text { Intolerantes }\end{array}$ & $\begin{array}{l}0,785 \\
0,722 \\
0,694 \\
0,537 \\
0,430\end{array}$ & $\begin{array}{l}0,751 \\
0,747 \\
0,687 \\
0,592 \\
0,555\end{array}$ & 2,675 & 5,691 & 66,673 \\
\hline $\begin{array}{c}8 \\
\text { Elitistas }\end{array}$ & $\begin{array}{c}\text { Discriminadores } \\
\text { Machistas } \\
\text { Racistas } \\
\text { Clasistas }\end{array}$ & $\begin{array}{l}0,717 \\
0,700 \\
0,696 \\
0,449\end{array}$ & $\begin{array}{l}0,705 \\
0,701 \\
0,664 \\
0,594\end{array}$ & 1,351 & 2,875 & 69,548 \\
\hline
\end{tabular}

Fuente: Elaboración propia.

El análisis de componentes principales es apropiado (con un nivel de confianza del $95 \%$ ), por cuanto en el test de adecuación de la muestra el valor de kmo $(0,892)$ cumple con la condición de ser mayor o igual a 0,5 . Además, se cumple con que la probabilidad $(0,000)$ asociada al test de Bartlett (p-value) es menor al nivel de significancia de 0,05 (Malhotra, 2004). Asimismo, el conjunto de variables cumplen con el requisito de tener varianza común con el componente (comunalidad de extrac- ción) como mínimo de 0,5 (Hair et al., 1998). Además, los 8 componentes explican un 69,548 \% de la varianza total, lo cual cumple con el mínimo exigido de un 60 \% (Malhotra, 2004). Junto con esto, la carga de cada variable con el componente (carga factorial) cumple con el mínimo exigido de 0,4 (Larwood et al., 1995).

Aun cuando el análisis de componentes principales es apropiado, esto no garantiza que los resultados obtenidos sean estadísticamente significativos. Así 
pues, es necesario analizar si el modelo propuesto presenta adecuados niveles de confiabilidad y validez. Se analizan los tipos de validez de contenido, divergente y convergente (Nunnally, 1978, 1987). Tal como se señaló anteriormente, se garantizó la validez de contenido con el análisis de estudios previos, la aplicación de cuestionarios semiestructurados, el uso de herramientas cualitativas y la opinión de expertos (Deng y Dart, 1994).

En lo que se refiere a la validez divergente, se realizó el análisis de correlación entre los factores obtenidos (dimensiones de personalidad), comprobando que los coeficientes de correlación son en todos los casos nulos (García y Ruiz, 2007). La validez de tipo convergente se consiguió a través del análisis de correlación entre la media de los valores de los ítems de la escala con la disposición de los jóvenes universitarios a inscribirse en los registros electorales, por cuanto se aseguró que existe correlación $(0,813)$ significativa (con un $99 \%$ de confianza) entre dos variables distintas del mismo fenómeno (Capelleras y Veciana, 2001).

En cuanto al análisis de confiabilidad, es posible sostener que existe consistencia interna en los constructos empleados para medir cada una de las dimensiones del modelo de personalidad de marca.
Esto porque las dimensiones de sinceridad $(0,768)$, ambición $(0,789)$, competencia $(0,739)$, estimulante $(0,858)$, tradicional $(0,830)$, sofisticado $(0,781)$, rudeza $(0,892)$ y elitistas $(0,831)$, presentan un valor alfa de Cronbach que es superior al límite inferior exigido de 0,6 (Hair et al., 1998).

Finalmente, los resultados permiten concluir que las dimensiones estratégicas presentan un buen grado de unidimensionalidad. En este proceso se eliminaron los ítems glamoroso de la dimensión sofisticado, serio de la dimensión tradicional, burocráticos de la dimensión competencia y clasistas de la dimensión elitista, ya que al hacerlo se mejoraba el análisis de confiabilidad (se incrementaba el valor alfa de Cronbach). Además, se eliminaron los ítems serviciales y generosos de la dimensión competencia, y los ítems entusiastas, juveniles, motivados y emocionantes de la dimensión estimulante. Lo anterior se debe a que estos ítems cargaban en un segundo factor (dimensión). En la tabla 5, se aprecia que los valores de kmo son mayores o igual a 0,5 (Malhotra, 2004), y los valores de la varianza explicada superiores a un 60 \% (Hair et al., 1998). Además, los indicadores (ítems) presentan cargas factoriales superiores al mínimo exigido de 0,4 (Larwood et al., 1995).

Tabla 5. Estadísticos de unidimensionalidad

\begin{tabular}{|c|c|c|c|c|c|}
\hline $\begin{array}{c}\text { Dimensiones de } \\
\text { personalidad }\end{array}$ & $\begin{array}{l}\text { Rasgos de } \\
\text { personalidad }\end{array}$ & $\begin{array}{l}\text { Carga } \\
\text { factorial }\end{array}$ & $\begin{array}{l}\text { Test de adecu- } \\
\text { ación de la } \\
\text { muestra (kmo) }\end{array}$ & $\begin{array}{c}\text { Varianza } \\
\text { explicada (\%) }\end{array}$ & Eigenvalue \\
\hline Sinceridad & $\begin{array}{c}\text { Honestos } \\
\text { Transparentes } \\
\text { Confiables } \\
\text { Éticos } \\
\text { Genuinos }\end{array}$ & $\begin{array}{l}0,781 \\
0,778 \\
0,738 \\
0,693 \\
0,633\end{array}$ & 0,788 & 52,791 & 2,640 \\
\hline Ambición & $\begin{array}{l}\text { Ambiciosos } \\
\text { Individualistas } \\
\text { Oportunistas } \\
\text { Egoístas }\end{array}$ & $\begin{array}{l}0,814 \\
0,811 \\
0,777 \\
0,734\end{array}$ & 0,755 & 61,564 & 2,463 \\
\hline Competencia & $\begin{array}{l}\text { Cumplidores } \\
\text { Eficientes } \\
\text { Responsables } \\
\text { Comprometidos } \\
\text { Preocupados } \\
\text { Prácticos } \\
\text { Competentes }\end{array}$ & $\begin{array}{l}0,781 \\
0,765 \\
0,745 \\
0,719 \\
0,714 \\
0,669 \\
0,641\end{array}$ & 0,759 & 51,915 & 3,634 \\
\hline
\end{tabular}


Universidad Pedagógica Nacional

Facultad de Humanidades

\begin{tabular}{|c|c|c|c|c|c|}
\hline Estimulante & $\begin{array}{c}\text { Originales } \\
\text { Creativos } \\
\text { Innovadores } \\
\text { Vanguardistas } \\
\text { Modernos } \\
\text { Apasionados } \\
\text { Entretenidos }\end{array}$ & $\begin{array}{l}0,843 \\
0,835 \\
0,808 \\
0,742 \\
0,709 \\
0,466 \\
0,419\end{array}$ & 0,837 & 50,050 & 3,504 \\
\hline Tradicional & $\begin{array}{l}\text { Conservadores } \\
\text { Tradicionales } \\
\text { Formales }\end{array}$ & $\begin{array}{l}0,907 \\
0,892 \\
0,822\end{array}$ & 0,758 & 76,482 & 2,294 \\
\hline Sofisticado & $\begin{array}{l}\text { Sofisticados } \\
\text { Elegantes }\end{array}$ & $\begin{array}{l}0,924 \\
0,924\end{array}$ & 0,500 & 85,303 & 1,706 \\
\hline Rudeza & $\begin{array}{c}\text { Agresivos } \\
\text { Peleadores } \\
\text { Conflictivos } \\
\text { Descalificadores } \\
\text { Intolerantes }\end{array}$ & $\begin{array}{l}0,861 \\
0,857 \\
0,856 \\
0,813 \\
0,792\end{array}$ & 0,846 & 69,970 & 3,499 \\
\hline Elitistas & $\begin{array}{c}\text { Discriminadores } \\
\text { Machistas } \\
\text { Racistas }\end{array}$ & $\begin{array}{l}0,902 \\
0,855 \\
0,840\end{array}$ & 0,701 & 75,035 & 2,251 \\
\hline
\end{tabular}

Fuente: Elaboración propia.

El modelo utilizado en la presente investigación tiene como base los resultados del estudio de Aaker (1997), pero se adapta a las características propias del país y del mercado sujeto a estudio. Esto se debe a lo señalado por Austin et al. (2003), a propósito de que es sumamente improbable que un esquema de investigación pueda ser desarrollado para que sea mundialmente generalizable a cualquier contexto en el cual la personalidad de marca o cualquier otro constructo relacionado con la marca deba ser medido.
Dado esto, se mantienen las 5 dimensiones consideradas en el estudio de Aaker (1997), pero se agregan otras tres (ambición, tradicional y elitistas) que hacen referencia a características propias del sujeto de estudio (los partidos políticos). Además, en el modelo propuesto se consideran otros rasgos de personalidad, los cuales hacen referencia a cualidades humanas que los jóvenes universitarios atribuyen a los partidos políticos (figura 2).

Figura 2. Modelo de personalidad de marca de los partidos políticos

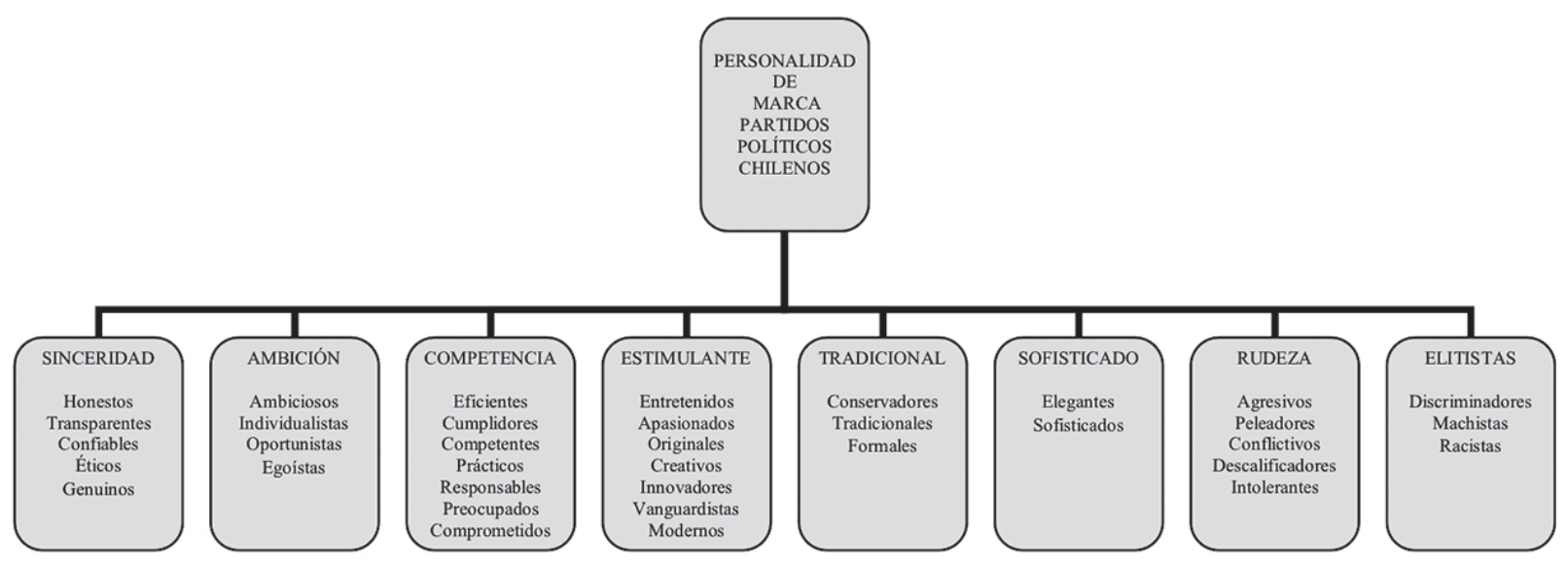

Fuente: Elaboración propia. 


\section{Conclusiones, implicancias y limitaciones}

Los sistemas políticos con democracias consolidadas se caracterizan por una baja participación ciudadana en los procesos eleccionarios. Esta situación trae consigo una serie de problemas para los gobiernos e instituciones políticas. Esto porque el padrón electoral se está envejeciendo en aquellos países que tienen una democracia consolidada y en donde los jóvenes no se sienten partes del sistema político. En estos países los jóvenes no se sienten representados por los partidos políticos, no sienten confianza en los actores políticos y consideran que su participación en los procesos eleccionarios no generará cambios. Esta situación genera un problema de legitimidad de los gobiernos y de los actores políticos.

Los jóvenes chilenos no participarán en política - y en los procesos eleccionarios - en la medida que los partidos políticos no mejoren el posicionamiento que tienen en la ciudadanía. Para esto, es necesario que los partidos políticos conozcan las necesidades de los electores jóvenes, y enfoquen recursos en acciones que permitan satisfacer las necesidades de este grupo de la población. No todos los partidos políticos deben realizar las mismas acciones y dirigirse a los mismos jóvenes, ya que en razón de sus principios ideológicos se dirigirán a distintos grupos de jóvenes. No obstante, todos los partidos políticos deben emprender acciones para mejorar la imagen de la política, ya que de esto depende que una gran cantidad de jóvenes que no se identifica con ningún bloque político, se puedan re-encantar con la política, y con esto que se solucione el problema de envejecimiento del padrón electoral.

Considerando lo anterior, la presente investigación propone un modelo teórico de personalidad de marca en los partidos políticos. La revisión de la literatura permite concluir que no se han propuesto escalas de personalidad de marca para los partidos políticos. En razón de esto se propone un modelo que considera los resultados de investigaciones previas que se han realizado en otros sectores de estudio. Sin embargo, existe consenso en que no se pueden replicar modelos de personalidad de marca que han sido desarrollados en diferentes contextos industriales y culturales. En este escenario, el modelo propuesto se adapta a las particularidades del sistema político de Chile y de los actores que lo componen. Con este objetivo, se propone un modelo que cumple con los requisitos de la validez de contenido, validez convergente y validez divergente. En este modelo la personalidad de marca de los partidos políticos se explica en función de las siguientes dimensiones: 1) sinceridad; 2) ambición; 3) competencia; 4) estimulante; 5) tradicional; 6) sofisticado; 7) rudeza; y 8) elitistas.

El modelo propuesto puede ser utilizado por los partidos políticos para conocer el posicionamiento que tienen dentro de los electores. Esto es particularmente relevante para conocer la percepción de los jóvenes, por cuanto son el grupo de la población que presenta una menor participación en los procesos democráticos. Con estos resultados los partidos políticos pueden diseñar estrategias de comunicación que se enfoquen en la mejora de posicionamiento en los rasgos de personalidad con connotación negativa, $y$ en el fortalecimiento de los rasgos en que tienen un buen posicionamiento. Lo anterior depende de los planteamientos y principios de los diferentes partidos. Los partidos políticos deben analizar los resultados de personalidad de marca en función de sus principios y valores, es decir, en función de la imagen que desean proyectar en la ciudadanía.

No obstante lo anterior, el modelo propuesto presenta algunas limitaciones. En primer lugar, la muestra está compuesta solo por jóvenes. Dado esto, los resultados no pueden ser replicados en otros grupos de la población sin realizar previamente un proceso de validación. Además, en la muestra solo se consideran a jóvenes universitarios. Lo anterior implica que los resultados no pueden ser generalizados para el total de la población joven. A pesar de esto, considerar en la muestra solo a jóvenes universitarios permite controlar la diferencia de resultados que se puede originar por el nivel de estudios. Asimismo, los jóvenes universitarios constituyen el grupo de estudio que presenta una mejor percepción y conocimiento sobre el sistema político y un mayor nivel de participación en los procesos eleccionarios (son los jóvenes con mayor nivel de participación en los procesos eleccionarios). 
Junto con esto, el modelo propuesto es teórico, por cuanto busca explicar la personalidad de marca de los partidos políticos con las dimensiones que son consideradas como más relevantes por los jóvenes universitarios. Considerando que es un modelo teórico, no se realiza la validación a través de la aplicación de ecuaciones estructurales. Esta situación se explica en el objetivo de la presente investigación, que es la propuesta de un modelo teórico que pueda ser validado en países con democracias que presenten similitud con la situación que se observa en Chile. A pesar de esto, en la presente investigación se aplica el análisis de pretest y de unidimensionalidad con el objetivo de realizar una validación estadística previa.

A pesar de las limitaciones expuestas, el modelo propuesto aporta a la literatura de personalidad de marca y a los estudios que buscan analizar las razones que han llevado a los jóvenes a automarginarse de la política. Aun cuando no es posible explicar la baja participación política de los jóvenes solo con la teoría de personalidad de marca, se presenta como una perspectiva alternativa en la explicación de un fenómeno que está cobrando cada vez más importancia en los países que tienen democracias consolidadas. En este escenario, el modelo propuesto puede ser adaptado a las características propias de cada sistema político y validado posteriormente a través del uso de ecuaciones estructurales. La futura investigación se centra en la validación de la escala de personalidad de marca de los partidos políticos. Se aplicará el cuestionario derivado del modelo en jóvenes que estudian en distintas universidades del país.

\section{Referencias}

Aaker, D. (1992). The value of brand equity. Journal of Business Strategy, 13(4), 27-32.

Aaker, D. (1996). Building Strong Brands. New York: The Free Press.

Aaker, D. (1997). Dimensions of brand personality. Journal of Marketing Research, 34, 347-356.

Aaker, J., Benet-Martinez, V., y Gorolera, J. (2001). Consumption symbols as carriers of culture: A study of Japanese and Spanish brand personality constructs. Journal of Personality and Social Psychology, 81(3), 492-508.

Akin, M. (2011). Predicting consumers' behavioral intentions with perceptions of brand personality: A study in cell phone markets. International Journal of Business and Management, 6(6), 193-206.

Allen, D., y Olson, J. (1995). Conceptualizing and creating brand personality: A narrative theory approach. En F. R. Kardes y M. Sujan (eds.), Advances in Consumer Research, 22. Provo, UT: Association for Consumer Research.

Alvarado, V., Ospina, H., Botero, P., y Muñoz, G. (2008). Las tramas de la subjetividad política y los desafíos a la formación ciudadana en jóvenes. Revista Argentina de Sociología, 11, 19-43.

Álvarez-Ortiz, C., y Harris, J. (2002). Assesing the structure of brand personality among global and local Mexican brands. AMA, Summer Educators Conference, San Diego, Estados Unidos.

Araya-Castillo, L. (2009). Grupos estratégicos en el mercado universitario chileno (Tesis para optar al título de Magíster en Marketing). Facultad de Economía y Negocios, Universidad de Chile, Chile.

Araya-Castillo, L., y Etchebarne, S. (2009). Personalidad de marca de los partidos políticos en Chile: Una mirada desde los jóvenes universitarios. Ponencia presentada en XXV Encuentro Nacional de Escuelas y Facultades de Administración y Economía (ENEFA), Antofagasta, Chile.

Araya-Castillo, L., y Pedreros-Gajardo, M. (2013). Usos del celular en jóvenes chilenos de bajos recursos. Revista Latinoamericana de Ciencias Sociales, Niñez y Juventud, 11(1), 109-121. 
Austin, J., Siguaw, J., y Mattila, A. (2003). A re-examination of the generalizability of the Aaker brand personality measurement framework. Journal of Strategic Marketing, 11, 77-92.

Balardini, S. A. (2005). ¿Qué hay de nuevo viejo? Una mirada sobre los cambios en la participación política juvenil. Nueva sociedad, 200, 96-107.

Barrientos, P. (2010). El marketing del partido político en el gobierno. Semestre Económico, 13(26), 119-134.

Barrios, M., y Massa, C. (1999). Dimensiones de la personalidad de marca en Venezuela (Tesis de Maestría). Instituto de Estudios Superiores de Administración, Caracas.

Batra, R., Donald, R. H., y Singh, D. (1993). The brand personality component of Brand Goodwill: Some antecedents and consequences. En D. A. Aaker y A. Biel, Brand equity and advertising. Hillsdale, NJ: Lawrence Erlbaum.

Batra, R., Lenk, P., y Wedel, M. (2005). Separating brand from category personality. University of Michigan. [Working Paper].

Beccassino, A. (2008). La nueva política. El entorno y la comunicación electoral. Bogotá: Aguilar.

Bendit, R. (2000). Participación social y política de los jóvenes en países de la Unión Europea. En S. Balardini (2000), La participación social y política de los jóvenes en el horizonte del nuevo siglo. Buenos Aires: CLACSO, Consejo Latinoamericano de Ciencias Sociales.

Blackett, T., y Harrison, T. (2001). Brand medicine: use and future potential of branding in pharmaceutical markets. International Journal of Medical Marketing, 2(1), 33-49.

Brunner, J., y Uribe, D. (2007). Mercados universitarios: el nuevo escenario de la educación superior. Santiago de Chile: Ediciones Universidad Diego Portales.

Capelleras, J. L., y Veciana, J. M. (2001). Calidad de servicio en la enseñanza universitaria: desarrollo y validación de una escala de medida (Documento de trabajo, 4). Departamento de Economía, Universidad Autónoma de Barcelona.

Caprara, G., Barbaranelli, C., y Guido, G. (1997). Personality as metaphor: Extension of the psycholexical hypothesis and the five factor model to brand and product personality description. European Advances in Consumer Research, 3, 61-69.
CIEPLAN, Libertad y Desarrollo, PNUD, Proyecta y CEP (2008). Estudio nacional sobre partidos políticos y sistema electoral. Disponible en: http://www.cep. cl/1_4105/doc/estudio_nacional_sobre_partidos_ politicos_y_sistema_electoral.html\#.VCy05fl_tPI

Colmenares, O., y Saavedra, J. (2008). Dimensiones de personalidad de marca. Caso de estudio: cadenas de farmacias. Revista Venezolana de Gerencia, 42, 220-232.

Dahl, R. (1971). Polyarchy. New Haven: Yale University Press.

Dahrendorf, R. (1997). After 1989. Morals, Revolution and Civil Society. Londres: Macmillan.

Deng, S., y Dart, J. (1994). Measuring market orientation: A multi-factor, multi-item approach. Journal of Marketing Management, 10(8), 725-742.

Denzin, N. K., y Lincoln, Y. S. (2000). The discipline and practice of qualitative research. Handbook of Qualitative Research. Thousand Oaks, CA: Sage Publications.

De WulF, K., y Odekerken-Schrode, G. (2003). Assessing the impact of a Retailers relationship efforts on consumer attitudes and behavior. Journal of Retailing and Consumer Services, 10, 95-108.

Downs, A. (1973). Teoría económica de la democracia. Madrid: Editorial Aguilar.

España, D., y Rivera, E. (2012). Los universitarios y la democracia en Bogotá: un caso de marketing político. Papel Político, 17(1), 15-55.

Fernández, G. (2000). Notas sobre la participación política de los jóvenes chilenos. En S. Balardini, La participación social y política de los jóvenes en el horizonte del nuevo siglo. Buenos Aires: CLACSO, Consejo Latinoamericano de Ciencias Sociales.

Freling, T. H., Crosno, J. L., y Henard, D. H. (2011). Brand personality appeal: conceptualization and empirical validation. Journal of the Academy of Marketing Science, 39(3), 392-406.

Gallo, G. (2000). Posicionamiento: El caso latinoamericano. Bogotá: McGraw-Hill Interamericana.

García, P. M. y Ruiz, M. (2007). Configuraciones organizativas en sectores dinámicos y hostiles: adecuación al contexto sectorial, coherencia interna y resultados. Cuadernos de Economía y Dirección de la Empresa, 32, 111-148. 
Haigood, T. L. (2001). Deconstructing Brand Personality. AMA Summer Educators Conference. Chicago.

Hair, J., Anderson, R., Tatham, R., y Black, W. (1998). Multivariate data analysis (Fifth Edition). New Jersey: Prentice Hall.

Hair, J., Black, W., Babin, B., Anderson, R., y Tatham, R. (2005). Multivariate data analysis (Sixth Edition). New Jersey: Prentice-Hall International.

Heere, B. (2010). A new approach to measure perceived brand personality associations among consumers. Sport Marketing Quaterly, 19(1), 17-24.

Hernani, M. (2008). Percepción de la personalidad de una marca global y de valores: un estudio comparativo entre consumidores brasileños y peruanos. Revista del Departamento Académico de Ciencias Administrativas, Pontificia Universidad Católica del Perú, 5, 44-54.

Hopenhayn, M. (2004). Participación juvenil y política pública: un modelo para armar. Trabalho apresentado no I Congresso da Associação Latino Americana de População, ALAP, realizadoem Caxambú- MG Brasil, de 18- 20 de Setembro de 2004.

Huneeus, C. (2000). Problemas de la participación política en América Latina. Una mirada desde Chile. Contribuciones, 15(1), 1-11.

Jensen, M. C., y Meckling, W. H. (1994). The nature of man. Journal of Applied Corporate Finance, 7(2), 4-19.

Jie, Y., Chou, T. J., y Chou, N. (2011). Assessing the fit of two brand personality scales in a Chinese context and revisiting the predictive validity of two methods of measuring self-congruity. Journal of Brand Management, 19(6), 525-540.

Keller, K. (1993). Conceptualising, measuring, and managing customer-based brand equity. Journal of Marketing, 57(1), 1-22.

Koebel, M. N., y Ladwein, R. (1999). Léchelle de personalité de la marque de Jennifer Aaker: Adaptation au contexte français. Décisions Marketing, 18, 81-88.

Lan, K., y Richey, K. (2006). The importance of corporate brand personality traits to a successful 21st century business. Journal of Brand Management, 14(1), 74-81.

Larwood, L., Falbe, C., Kriger, M., y Miesing, P. (1995). Structure and Meaning of organizational Vision. Academy of Management Journal, 38(3), 740-769.

Lenk, P., Batra, R., y Wedel, M. (2003). Representing brand and category personality with circumplex models. University of Michigan Business School. [Working Paper].
Malhotra, N. (2004). Investigación de mercados (4. ${ }^{\mathrm{a}}$ Edición). México: Pearson Educación.

Martínez, M. L., Silva, C., y Hernández, A. C. (2010). ¿En qué ciudadanía creen los jóvenes? Creencias, aspiraciones de ciudadanía y motivaciones para la participación sociopolítica. Psykhe (Santiago), 19(2), 25-37.

Müller, B., y Chandon, J. L. (2003). The impact of visiting a brand website on brand personality. Electronic Markets, 13(3), 210-221.

Muller Muniz, K., y Zancan Marchetti, R. (2012). Brand personality dimensions in the Brazilian context. BAR, Brazilian Administration Review, 9(2), 168-188.

Nguyen, T. A. (2013). Study about brand personality of nonprofit organization in Sweden (Bachelor Thesis). School of Business and Economics, Linnaeus University, Sweden.

Nunnally, J. (1978). Psychometric theory (Second Edition). New York: McGraw-Hill.

Nunnally, J. (1987). Teoría psicométrica. México: Trillas.

Olavarrieta, S., Friedmann, R., y Manzur, E. (2010). Brand personality in Chile: a combined emic-etic approach. Estudios de Administración, 17(1), 25-50.

Owlia, M. S., y Aspinwall, E. M. (1998). A framework for measuring quality in engineering education. Total Quality Management, 9(6), 501-518.

Pirela, J., Villavicencio, H., y Saavedra, J. (2004). Dimensiones de personalidad de marca. Estudio exploratorio de los rasgos de personalidad en Venezuela. Revista de Ciencias Sociales, 10(3), 430-440.

Rojas-Méndez, J. (2007). La personalidad de la marcapaís como eje para el desarrollo de ventajas competitivas. Disponible en: http://www.comexperu.org. pe/archivos\%5Cforo\%5Cforo_17042007/Jose\%20 Rojas-Mendez_w.pdf

Saavedra, J., Colmenares, O., y Pirela, J. L. (2007). Correlación entre dimensiones de personalidad de marca y la marca emocional. Estudio en Cadena de Farmacias. Revista de Ciencias Sociales, 13(2), 219-229.

Saavedra, J. L., Pirela, J. L., y Colmenares, O. (2008). Determinación de personalidad de marca del venezolano. Revista Debates IESA, 13(2), 48-52.

Saavedra, J., Urdaneta, D., Pirela, J. L., y Colmenares, O. (2008). Medición de la personalidad de marca en el mercado automotriz. Revista Visión General, 1, 183-196. 
Sánchez, M. y Sarabia, F. J. (1999). Validez y fiabilidad de escalas. En F. J. Sarabia (coord.), Metodología para la investigación en marketing y dirección de empresas. Madrid: Ediciones Pirámide Ciudad.

Sandoval, M. (2000). La relación entre los cambios culturales de fines de siglo y la participación social y política de los jóvenes. En S. Balardini, $L a$ participación social y política de los jóvenes en el horizonte del nuevo siglo. Buenos Aires: CLACSO, Consejo Latinoamericano de Ciencias Sociales.

Schlesinger, M. W., y Cervera, A. (2008). Estudio comparativo entre personalidad de marca ideal $v s$. percibida: aplicación a las compañías aéreas. Innovar, 18(31), 61-76.

Schlesinger, M. W., Cervera, A., y Yagüe, M. J. (2013). Estudio comparativo de la personalidad de marca percibida de las compañías aéreas españolas. Estudios Turísticos, 197, 83-105.

Schumpeter, J. (1942). Capitalism, socialism and democracy. Nueva York: Harper and Row.

Stanton, W., Etzel, M., y Walker, B. (2000). Fundamentos de Marketing (11. ${ }^{a}$ Edición). México: McGraw-Hill.

Toldos, M. (2012). Dimensions of brand personality in Mexico. Global Journal of Business Research, 6(5), $35-47$.

Toldos, M., y Castro, M. (2013). El efecto de las dimensiones de personalidad de marca en la intención de compra de marcas de lujo en México y Brasil. Global Conference on Business \& Finance Proceedings, 8(2), 837-842.

Torres, E., y Araya-Castillo, L. (2010). Construcción de una escala para medir la calidad del servicio de las universidades: Una aplicación al contexto chileno. Revista de Ciencias Sociales, 16(1), 54-67.

Valenzuela, A. (2008). Los partidos políticos y los desafíos de la gobernabilidad democrática en América Latina. En A. Fontaine, C. Larroulet, J. Navarrete, I. Walker, Reforma de los partidos politicos en Chile. Santiago de Chile: PNUD, CER, Libertad y Desarrollo, Proyectamérica y CIEPLAN.

Valdez, A., Huerta, D., y Vergara, A. (2012). Del marketing político tradicional al marketing 2.0. Revista Mexicana de Comunicación, 49-53.

Zapata, P. (2008). Representatividad de los partidos políticos. En A. Fontaine, C. Larroulet, J. Navarrete e I. Walker (eds.), Reforma de los partidos políticos en Chile. Santiago de Chile: PNUD, CER, Libertad y Desarrollo, Proyectamérica y CIEPLAN. 